\title{
Comparative Study of Surface Modification Treatment for Porous Titanium
}

\author{
Reiko Kobatake ${ }^{1}$, Kazuya Doi ${ }^{1}$, Yoshifumi Oki ${ }^{1}$, Yusuke Makihara ${ }^{1}$, Hanako Umehara ${ }^{1}$, \\ Takayasu Kubo ${ }^{1}$, Kazuhiro Tsuga ${ }^{1}$
}

${ }^{1}$ Department of Advanced Prosthodontics, Hiroshima University Graduate School of Biomedical and Health Sciences, Hiroshima, Japan.

\author{
Corresponding Author: \\ Reiko Kobatake \\ Department of Advanced Prosthodontics \\ Hiroshima University Graduate School of Biomedical and Health Sciences \\ 1-2-3, Kasumi, Minami-ku, Hiroshima 734-8553 \\ Japan \\ Phone: +81822575677 \\ Fax: +81822575679 \\ E-mail: reiko1122@hiroshima-u.ac.jp
}

\begin{abstract}
Objectives: This study was to investigate suitable surface treatment methods for porous titanium by ex vivo study of material properties and calcium phosphate deposition in simulated body fluid.

Material and Methods: Porous titanium with acid $\left(\mathrm{H}_{2} \mathrm{SO}_{4}\right.$ and $\mathrm{HCl}$ mixed acid) or alkali $(\mathrm{NaOH})$ treatment was prepared. The surfaces were observed, and the weight change ratio (after and before surface treatment) and compression strength were measured. To investigate the apatite formation ability, each sample was immersed in simulated body fluid (SBF). Surface observations were performed, and the weight change ratio (before/after immersing SBF) and calcification (by alizarin red staining) were measured.

Results: The acid group showed a martensitic micro-scale rough structure and the weight and mechanical strength greatly decreased compared to the other groups. The alkali group exhibited a nano-scale roughness structure with similar weight and mechanical strength. Following immersion in SBF, an apatite-like crystal layer in the alkali group was observed. The weight of all samples increased. The change in weight of the samples in the alkali, acid, and control groups were significantly different, showing the following trend: alkali group $(1.6 \%)>$ acid group $(1.2 \%)>$ control group $(0.8 \%)$. Calcium precipitation values were higher in the samples from alkali group than in those from the acid and control groups.

Conclusions: Alkali treatment was found to be a suitable surface modification method for porous titanium, resulting in good mechanical strength and apatite formation ability in simulated body fluid.
\end{abstract}

Keywords: alkalies; biocompatible materials; titanium.

\author{
Accepted for publication: 4 June 2020 \\ To cite this article: \\ Kobatake R, Doi K, Oki Y, Makihara Y, Umehara H, Kubo T, Tsuga K. \\ Comparative Study of Surface Modification Treatment for Porous Titanium \\ J Oral Maxillofac Res 2020;11(2):e5 \\ URL: http://www.ejomr.org/JOMR/archives/2020/2/e5/v11n2e5.pdf \\ doi: $10.5037 /$ jomr.2020.11205
}




\section{INTRODUCTION}

Porous metals are biomaterials with high mechanical strength and can be used in load-bearing applications $[\underline{1}, \underline{2}]$. Porous titanium has an interconnected threedimensional porous structure and exhibits good biocompatibility and osteoconductive abilities. Titanium causes the precipitation of calciumphosphate (Ca-P) on its surface in simulated body fluid (SBF), contributing to integration with bone in vivo [3] . However, titanium is a bio-inert material $[\underline{4}, \underline{5}]$. Thus, titanium has no osteoinductive ability and does not enhance bone formation.

Various methods have been applied to modify the surface of titanium [6,7]. Surface topographies such as roughness or charge affect osteoconductivity and osseointegration [8-10]. Mechanical treatment with grit blasting or plasm spraying may modify the titanium surface topography. These methods are often applied to solid titanium such as dental implants, titanium plates, and artificial joints. However, it is difficult to apply these methods to porous structures, because their effective range, which is limited to the surface layer and prevents uniform treatment of the porous matrix surface.

There are various reports of the chemical treatment of titanium, including acid etching or alkali treatment [3, 11-14], allowing the chemical to penetrate porous metal structures uniformly. Furthermore, these treatments modify titanium surfaces, converting them from bioinert to bioactive [15].

However, acid treatment severely corrodes titanium thin membrane [16]. The structure and mechanical strength after acid treatment are considerably changed compared to those after alkali treatment. Thus, the corrosion effect of acid on the thin framework of porous titanium limits its applications.

The aim of this study was to investigate suitable surface treatment methods for porous titanium by ex vivo study of material properties and calcium phosphate deposition in simulated body fluid.

\section{MATERIAL AND METHODS Sample preparation}

Twenty-seven porous shaped pure titanium (porous titanium, purity 99.7\%) disk types (diameter 13 $\mathrm{mm} \times$ thickness $2 \mathrm{~mm}, 85 \%$ porosity) were used for surface modification (Figure 1). Porous titanium samples were fabricated using a resin-impregnated titanium substitution technique [17]; the base urethane foam was soaked into the slurry with pure titanium powders, and heat to eliminate urethane before be sintering.

The surface treatment was performed as follows. Control group samples were washed in an ultrasonic cleaner with acetone and distilled water for $1 \mathrm{~h}$ each and dried in a $37^{\circ} \mathrm{C}$ oven overnight. The acid group samples were immersed in a $20 \mathrm{~mL} /$ disk mixture of $10.6 \% \mathrm{HCl}$ and $66.3 \% \mathrm{H}_{2} \mathrm{SO}_{4}(=1: 1)$

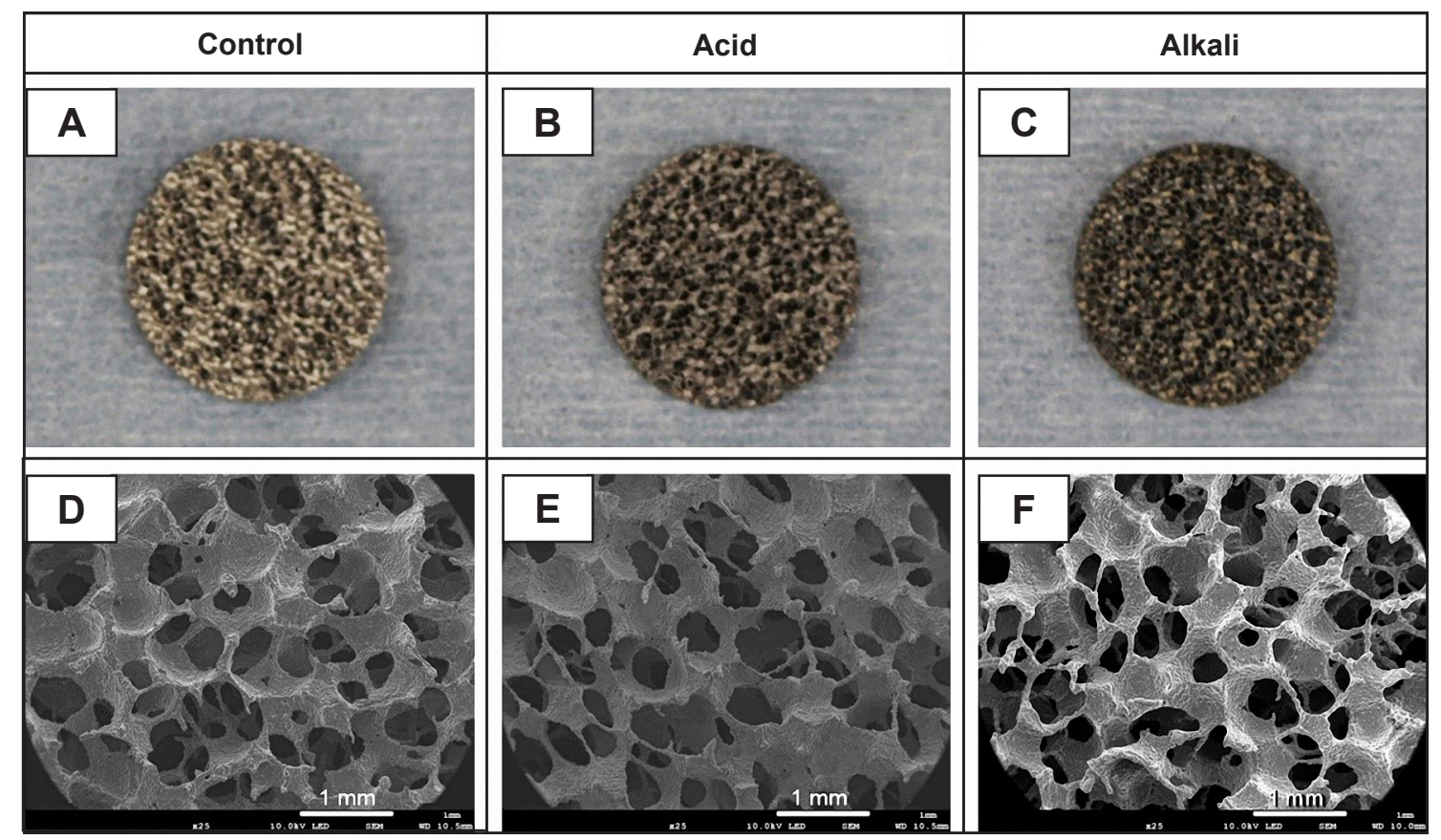

Figure 1. Surface structures of test samples: $\mathrm{A}$ and $\mathrm{D}=$ control; $\mathrm{B}$ and $\mathrm{E}=$ acid; $\mathrm{C}$ and $\mathrm{F}=$ alkali.

$\mathrm{A}, \mathrm{B}$ and $\mathrm{C}=$ outer structure (diameter: $13 \mathrm{~mm}$; height: $2 \mathrm{~mm}$ ); $\mathrm{D}, \mathrm{E}$ and $\mathrm{F}=$ scanning electron microscopy images (original magnification $\mathrm{x} 25$ ). All samples had interconnected porous structures. 
and by incubating them at $60^{\circ} \mathrm{C}$ for $1 \mathrm{~h}$ with gentle shaking after washing as in the control group. The disks in the alkali group were immersed in $20 \mathrm{~mL} /$ disk of $5 \mathrm{~N} \mathrm{NaOH}$, and incubated at $60^{\circ} \mathrm{C}$ for $24 \mathrm{~h}$ with gentle shaking after washing as in the control group. After incubation in acid or alkali solution, the disks were washed with distilled water for $1 \mathrm{~h}$ and dried in a $37^{\circ} \mathrm{C}$ oven.

\section{Evaluation of surface structure}

The structure of each treated porous titanium sample was evaluated. Samples were set on the stage with carbon adhesive tape and examined by scanning electron microscopy (SEM) (JSM-7200F - JEOL Ltd.; Tokyo, Japan).

\section{Local elemental analysis}

An electron probe micro-analyser (EPMA) (EPMA$1720 \mathrm{H}$ - Shimadzu Corporation; Kyoto, Japan) was used for elemental quantitative analysis. Each sample was fixed on the stage with carbon tape. The conditions were as follows: acceleration voltage 15.0 $\mathrm{kV}$ and aperture size $100 \mu \mathrm{m}$.

\section{Measurement of mechanical strength}

Each sample was set on the stage and the cross-head speed was $0.5 \mathrm{~mm} / \mathrm{min}$. The first peak load value $(\mathrm{N})$ of each sample was determined as the compression strength (AUTO GRAPH AGS-X - Shimadzu Corporation; Kyoto, Japan). The compression strength was then recorded as the mechanical strength (MPa) $(n=4)$.

\section{Evaluation of apatite formation ability}

Hanks' balanced salt solution without phenol red (Lonza Walkersville Inc; Maryland, USA) with ion concentrations nearly equal to those in human body fluid was prepared, and each sample was immersed in $2.5 \mathrm{~mL}$ of $\mathrm{SBF}$ at $37^{\circ} \mathrm{C}$. Samples were immersed for a period of 7 days, and the SBF solution was changed daily during this period. Subsequently, the samples were gently washed with distilled water and dried in a $37^{\circ} \mathrm{C}$ oven.

\section{Observation of precipitate structure}

A sample from each group was attached to a stage with carbon adhesive tape and imaged by SEM. All samples were sputter-coated with platinum before observation.

\section{Weight change ratio before and after surface treatment and immersion in SBF}

The weights of the samples before and after surface treatment and SBF immersion were measured using an electronic balance (AUW120D - Shimadzu Corporation; Kyoto, Japan). Based on the data obtained, the weight increase ratio was calculated for each sample $(\%=$ after/before surface treatment or SBF immersion $\times 100)($ surface treatment: $n=4, S B F$ immersion: $\mathrm{n}=5$ ).

\section{Measurement of calcification}

The samples were immersed in a 24-well plate $(0.5$ $\mathrm{mL} /$ well) containing alizarin red (ARD-A1 - PG Research Co., Ltd.; Tokyo, Japan) and stained for $30 \mathrm{~min}$ at room temperature. The samples were then washed with distilled water to stop the staining. Excess distilled water in the well was drained as much as possible, and then, $0.5 \mathrm{~mL} /$ well of calcified nodule dissolution solution (ARD-E1 - PG Research Co., Ltd.; Tokyo, Japan) was added to each well. Then the solution was stirred for $10 \mathrm{~min}$, and the dye was eluted. The eluate $(100 \mu \mathrm{L})$ was transferred into a 96well plate and the absorbance of these eluates was measured at $450 \mathrm{~nm}(\mathrm{n}=4)$.

\section{Statistical analyses}

All data were analysed at the 5\% significance level using one-way analysis of variance followed by Tukey's post hoc test. The results were expressed as the mean and standard deviation (M [SD]).

\section{RESULTS \\ Evaluation of surface structure}

Materials in all groups appeared to have similar outer structure (Figure 1A - C). At low magnification scanning electron microscopy (SEM) images, they were also similar structures; each pore was interconnected and the pore size was about 300 $\mu \mathrm{m}$ diameter (Figure 1D - F). Based on high magnification, the titanium powder structure could be observed in the control group (Figure 2A) and the surface was smooth (Figure 2D). The titanium powder shape was not observed in the acid group (Figure 2B) and the surface had a micro-scale rough structure (Figure 2E). In the alkali group, the titanium powder shape was observed (Figure 2C), and surface observations indicated nano-scale roughness with a three-dimensional structure (Figure 2F). 


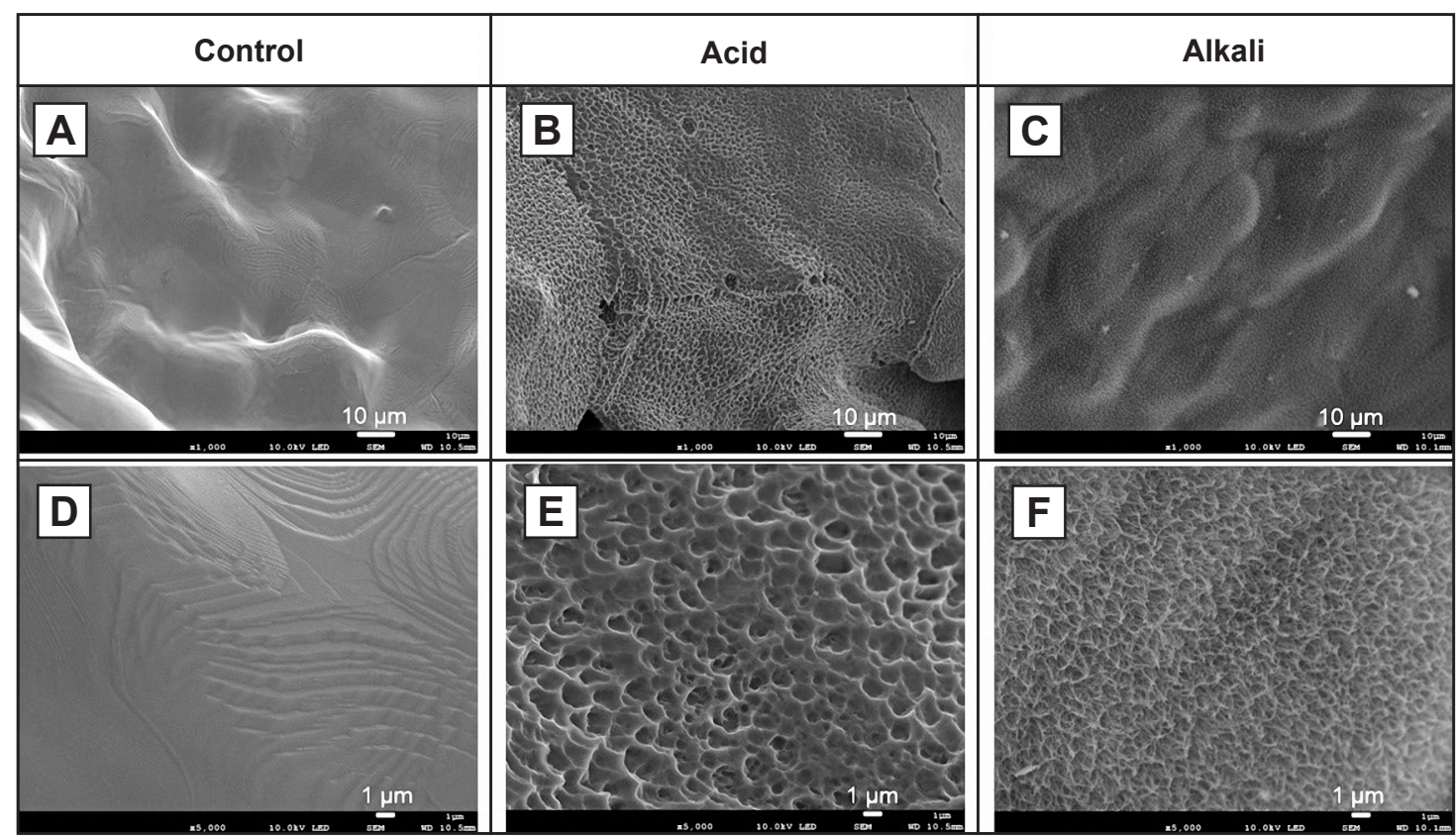

Figure 2. Surface structure of samples in scanning electron microscopy images: A, B and C = original magnification $\mathrm{x} 1000 ; \mathrm{D}, \mathrm{E}$ and $\mathrm{F}=$ original magnification $\mathrm{x} 5000$.

$\mathrm{A}$ and $\mathrm{D}=$ control. Ttitanium powder shape was observed, and the surface was smooth.

$\mathrm{B}$ and $\mathrm{E}=$ acid. No titanium powder shape was observed. Micro-scale roughness structure was observed.

$\mathrm{C}$ and $\mathrm{F}=$ alkali. A titanium powder shape was observed. A nano-scale rough structure was observed.

\section{Local elemental analysis}

Elemental distribution characterised by an EPMA on the surface is shown in Table 1. In the control sample, $16.43 \%$ carbon $(\mathrm{C})$, representing the adhesion of organic dirt was detected and the surface also bound to nitrogen $(\mathrm{N})$ in the atmosphere. In the acid-treated sample, the $\mathrm{C}$ contamination was decreased to $0.62 \%$. In alkali sample, $\mathrm{C}$ contamination was also decreased to $3.16 \%$. Oxygen $(\mathrm{O})$ was increased to $29.25 \%$ and sodium $(\mathrm{Na})$ was detected.

\section{Compressive strength}

The compressive strength of the acid group was significantly lower than that of the control.

Table 1. Elemental quantitative analysis

\begin{tabular}{c|c|c|c}
\hline Elements & Control & Acid & Alkali \\
\hline $\mathbf{C}$ & 16.43 & 0.62 & 3.16 \\
\hline $\mathbf{N}$ & 14.73 & 16.72 & 9.26 \\
\hline $\mathbf{O}$ & - & - & 29.25 \\
\hline $\mathbf{N a}$ & - & - & 0.65 \\
\hline $\mathbf{S i}$ & 1.58 & 0.28 & 0.77 \\
\hline $\mathbf{S}$ & - & - & 0.18 \\
\hline $\mathbf{C l}$ & - & - & - \\
\hline $\mathbf{C a}$ & - & - & 0.08 \\
\hline $\mathbf{T i}$ & 66.65 & 82.38 & 55.66 \\
\hline $\mathbf{C r}$ & 0.39 & - & 0.43 \\
\hline $\mathbf{F e}$ & 0.21 & - & 0.56 \\
\hline
\end{tabular}

There were no significant differences between the control and the alkali groups (Figure 3).

\section{Observation of precipitate structure}

A small surface precipitation layer was observed in the samples from the control group, and the crystal structure was sparse and few (Figure 4A, D). In the acid and alkali groups, there were numerous spherical precipitations on the surface layer of the samples (Figure 4B, C). At higher magnifications,

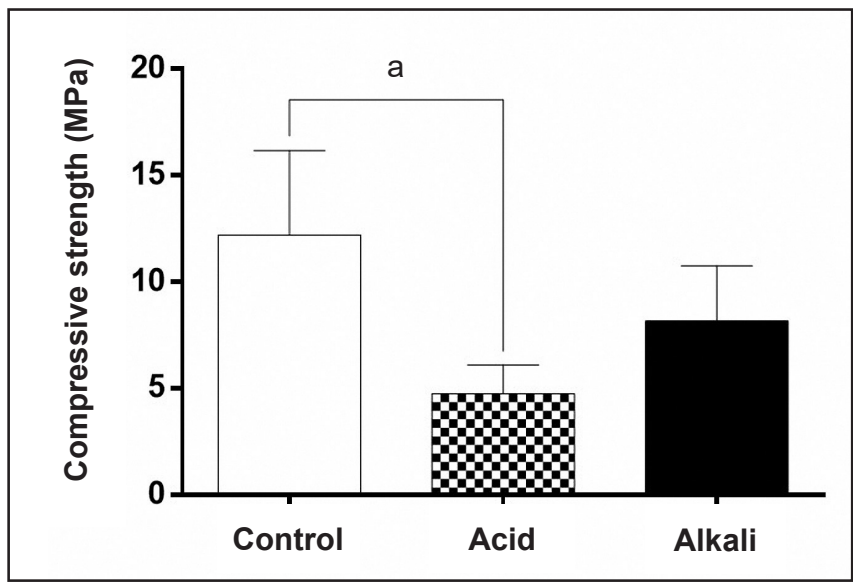

Figure 3. Compressive strengths among test samples.

The compressive strength of the acid samples was significantly lower than that of the control group, whereas that of the alkali was not significantly different from that of the control.

Mean and standard deviations were shown. aP $<0.05$ vs distant region. 


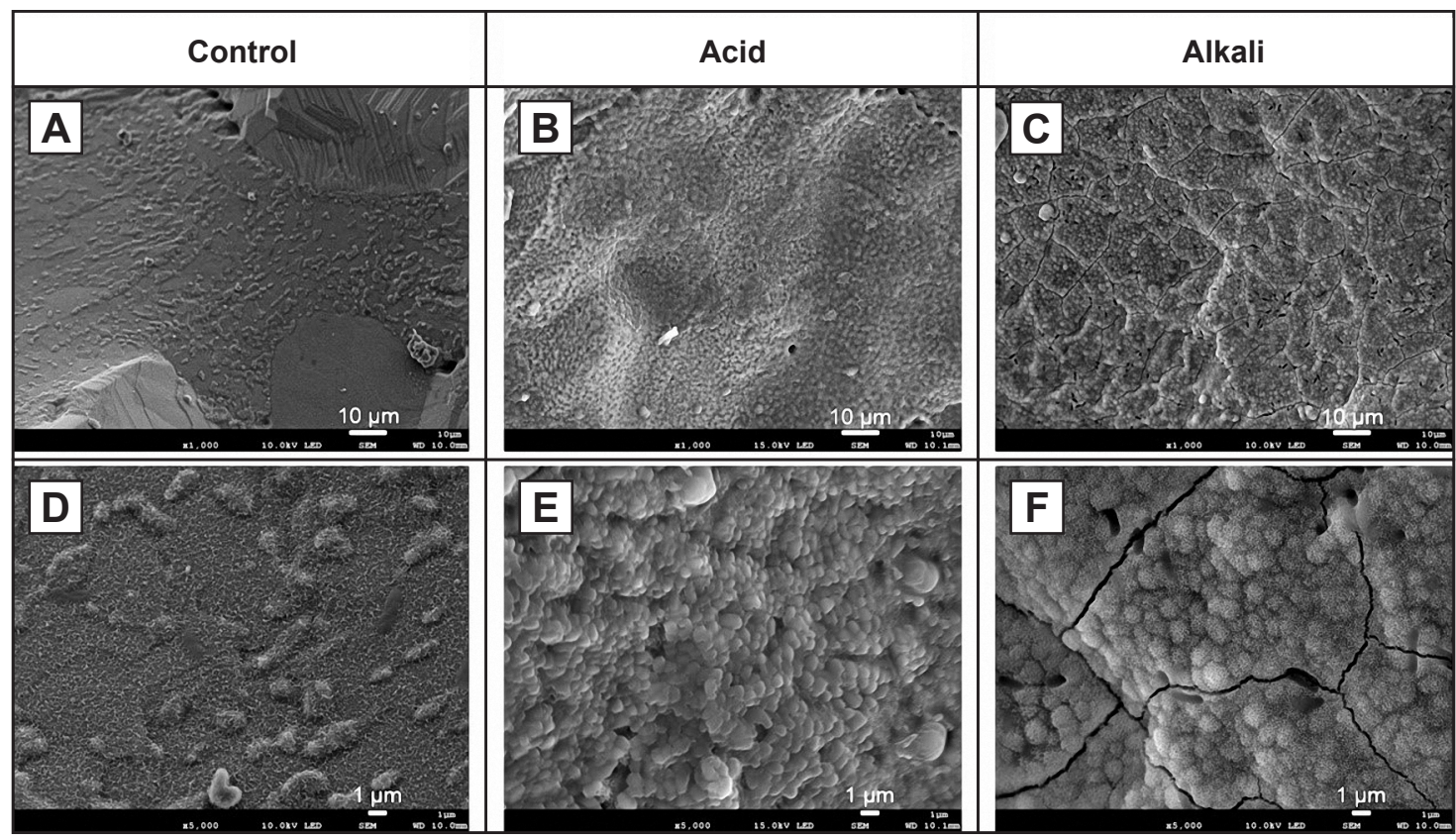

Figure 4. Surface precipitate structures of test samples: A, B and C = original magnification $\mathrm{x} 1000 ; \mathrm{D}, \mathrm{E}$ and $\mathrm{F}=$ original magnification x5000. Scanning electron microscopy images observations after immersing in simulated body fluid.

$\mathrm{A}$ and $\mathrm{D}=$ control. Showing little surface deposition.

$\mathrm{B}$ and $\mathrm{E}=$ acid. Numerous spherical precipitations and surface depositions.

$\mathrm{C}$ and $\mathrm{F}=$ alkali. Numerous spherical precipitations and surface depositions and apatite-like.

numerous structures that were close to spherical were observed in on the surfaces of the samples from the acid and alkali surface groups (Figure 4E, F). Particularly in alkali, apatite-like crystal spherical structures were detected and were very thick and cracked (Figure 4F).

\section{Weight change ratio before and after surface treatment and immersion in SBF}

In control group, after washing with acetone and distilled water, the weight was reduced slightly. After acid treatment, the weight of the samples was significantly reduced, compared to that of the control and the alkali groups. After alkali treatment, the weight of samples was increased, and the ratio was higher than that of the samples of acid group. There were no significant differences between the control and the alkali groups. The weight of all samples increased following immersion in SBF. The weights significantly increased in the order of the alkali, acid, and control groups (Table 2).

\section{Measurement of calcification}

In the alkali group, this value was significantly higher than that in the acid and control groups. There was no significant difference between the acid and control groups (Table 2).
Table 2. After/before surface treatment and simulated body fluid treatment

\begin{tabular}{|c|c|c|c|}
\hline \multirow{3}{*}{ Group } & \multicolumn{2}{|c|}{ Change in weight $(\%)$} & \multirow[b]{2}{*}{ Absorbance } \\
\hline & $\begin{array}{c}\text { After/before } \\
\text { surface treatment }\end{array}$ & $\begin{array}{c}\text { After/before } \\
\text { SBF treatment }\end{array}$ & \\
\hline & Mean (SD) & Mean (SD) & Mean (SD) \\
\hline Control & $-0.1(0.14)^{\mathrm{a}}$ & $0.8(0.2)^{\mathrm{d}}$ & $0.037(0.001)^{\mathrm{g}}$ \\
\hline Acid & $-5.2(0.53)^{b}$ & $1.2(0.2)^{\mathrm{e}}$ & $0.038(0.001)^{\mathrm{h}}$ \\
\hline Alkali & $0.4(0.15)^{\mathrm{c}}$ & $1.6(0.1)^{\mathrm{f}}$ & $0.041(0.001)^{\mathrm{i}}$ \\
\hline
\end{tabular}

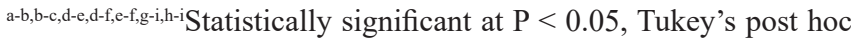
test

${ }^{a-c, g-\text {-h }}$ Not statistically significant at $\mathrm{P}<0.05$, Tukey's post hoc test. $\mathrm{SD}=$ standard deviation

\section{DISCUSSION}

The present study demonstrated that acid treatment reduced carbonate contamination and the mechanical strength of porous titanium. We used $85 \%$ porosity porous titanium, which has an approximately $300 \mu \mathrm{m}$ pore size because it is suitable for bone formation and has good mechanical strength. The surface treatment was previously described being effective for titanium bioactive treatment.

Alkali treatment also reduced contamination and resulted in precipitation of a sodium titanate surface layer without significantly reducing mechanical strength. Furthermore, alkali treatment of porous 
titanium resulted in the successful formation of crystalline Ca-P compound structures following SBF immersion.

The surface oxide layer is important for improving the biocompatibility of titanium, therefore, chemical treatments were used to modify porous titanium surfaces [18,19]. Titanium exhibited excellent corrosion resistance [20,21]. However, it was corroded under strong acidic conditions up to $\mathrm{pH} 3$ [22] becoming rougher and corroded on the surface.

As shown in the SEM images, acid treatment created a martensitic micro-scale pore structure on the surface. The weight change ratio and mechanical strength were both reduced by acid treatment. The framework of porous titanium is much thinner than that of a solid structure such as a titanium plate or implant; thus, the corrosion effect was considered as severe. These results agree with those observed thin titanium [16].

EPMA analysis revealed that the carbon elements detected on the titanium surface were decreased after surface chemical treatment. Surface contamination with carbonate results in downregulation of adhesion proteins and osteocalcin expression [23]. Titanium is known to resist corrosion in the presence of alkali solutions under low-temperature conditions. However, it is slightly corroded by an alkali solution under thermal-temperature conditions. $\mathrm{NaOH}$ treatment resulted in the formation of a sodium hydrogen titanate layer on the titanium surface. Based on the SEM images, alkali treatment created a nano-scale uniform porous network structure on the surface, formed by the titanate layer and slight corrosion. This observed topography was consistent with that from other reports of alkali-treated solid titanium structures $[24,25]$. Thus, the weight change ratio was slightly increased and mechanical strength was slightly decreased. However, there were no significant differences between the alkali treatment and control groups. The weight change ratio of the control group was measured after/before washing with acetone and distilled water for $1 \mathrm{~h}$ each. After acetone washing, the surface carbonate was removed, and the weight was slightly decreased.

Kokubo et al. $[\underline{3}, 15]$ reported that bioactive titanium surfaces precipitate a calcium phosphate layer after immersion in SBF and that this phenomenon is used to evaluate the apatite formation abilities. The mechanism of Ca-P compound formation is as follows: $\mathrm{Na}^{+}$on the titanium surface is exchanged with $\mathrm{H}_{3} \mathrm{O}^{+}$in $\mathrm{SBF}$, and $\mathrm{Na}^{+}$is released. Next, Ti$\mathrm{OH}$ groups are formed on the surface, which are involved in Ca-P compound nucleation. Additionally, with an increase in the $\mathrm{pH}$, negatively charged Ti$\mathrm{OH}$ groups preferentially combine with the $\mathrm{Ca}^{2+}$ in the SBF [26]. SEM imaging of acid and alkali groups revealed that numerous spherical precipitated surface $\mathrm{Ca}-\mathrm{P}$ compound layers. This finding was consistent with the weight change ratio after/before immersing in SBF solution. The weight ratio indicates the amount of precipitation and was higher in the acid and alkali group than in the control.

Alizarin red $\mathrm{S}$ is used to stain deposited calcium phosphate, and is thus used for colorimetric testing of calcification. The optical absorbance of the acid and alkali groups was significantly higher than that of the control, which agrees with the weight increase ratio observed after/before SBF treatment. The process of calcium precipitation is as follows: the alkalitreated sodium hydrogen titanate surface is negatively charged because positively charged sodium ions are easily released. The negatively charged surface combines with positively charged calcium ions in the SBF, which then combine with negatively charged phosphate ions, resulting in formation of a Ca-P layer. The Ca-P layer eventually transforms into a stable crystalline bone-like apatite [15]. In contrast, as the acid-treated titanium surface is positively charged, it combines with phosphate ions and calcium ions to form an apatite layer [27]. As the acid-treated surface combines with phosphate ions before calcium ions, there may be insufficient calcium precipitation over the 7-day immersion period compared to that with alkali-treated surfaces.

\section{CONCLUSIONS}

Acid treatment of porous titanium caused a reduction in its mechanical strength. In contrast, alkali-treated porous titanium had good apatite formation ability in simulated body fluid without causing a reduction in its mechanical strength. Based on these findings, alkali treatment is a suitable surface modification method for porous titanium.

\section{ACKNOWLEDGMENTS AND DISCLOSURE STATEMENTS}

The authors report no conflicts of interest related to this study. This study was supported by a Scientific Research Grant (No. 18K09683 and 19J13235) from the Japan Society for the Promotion of Science. 


\section{REFERENCES}

1. den Boer FC, Wippermann BW, Blokhuis TJ, Patka P, Bakker FC, Haarman HJ. Healing of segmental bone defects with granular porous hydroxyapatite augmented with recombinant human osteogenic protein-1 or autologous bone marrow. $\mathrm{J}$ Orthop Res. 2003 May;21(3):521-8. [Medline: 12706026] [doi: 10.1016/S0736-0266(02)00205-X]

2. Fujibayashi S, Kim HM, Neo M, Uchida M, Kokubo T, Nakamura T. Repair of segmental long bone defect in rabbit femur using bioactive titanium cylindrical mesh cage. Biomaterials. 2003 Sep;24(20):3445-51. [Medline: 12809773] [doi: 10.1016/S0142-9612(03)00221-7]

3. Kokubo T, Miyaji F, Kim HM, Nakamura T. Spontaneous Formation of Bonelike Apatite Layer on Chemically Treated Titanium Metals. J Am Ceram Soc. 1996 Apr;79(4):1127-9. [doi: 10.1111/j.1151-2916.1996.tb08561.x]

4. Cole BJ, Bostrom MP, Pritchard TL, Sumner DR, Tomin E, Lane JM, Weiland AJ. Use of bone morphogenetic protein 2 on ectopic porous coated implants in the rat. Clin Orthop Relat Res. 1997 Dec;(345):219-28. [Medline: 9418644] [doi: 10.1097/00003086-199712000-00032]

5. Ferretti C, Ripamonti U. Human segmental mandibular defects treated with naturally derived bone morphogenetic proteins. J Craniofac Surg. 2002 May;13(3):434-44. [Medline: 12040215] [doi: 10.1097/00001665-200205000-00014]

6. Le Guéhennec L, Soueidan A, Layrolle P, Amouriq Y. Surface treatments of titanium dental implants for rapid osseointegration. Dent Mater. 2007 Jul;23(7):844-54. [Medline: 16904738] [doi: 10.1016/j.dental.2006.06.025]

7. Jemat A, Ghazali MJ, Razali M, Otsuka Y. Surface Modifications and Their Effects on Titanium Dental Implants. Biomed Res Int. 2015;2015:791725. [Medline: 26436097] [PMC free article: 4575991] [doi: 10.1155/2015/791725]

8. He FM, Yang GL, Li YN, Wang XX, Zhao SF. Early bone response to sandblasted, dual acid-etched and $\mathrm{H} 2 \mathrm{O} 2 / \mathrm{HCl}$ treated titanium implants: an experimental study in the rabbit. Int J Oral Maxillofac Surg. 2009 Jun;38(6):677-81. [Medline: 19406618] [doi: 10.1016/j.ijom.2009.03.716]

9. Salou L, Hoornaert A, Louarn G, Layrolle P. Enhanced osseointegration of titanium implants with nanostructured surfaces: an experimental study in rabbits. Acta Biomater. 2015 Jan;11:494-502. [Medline: 25449926] [doi: 10.1016/j.actbio.2014.10.017]

10. Khosravi N, Maeda A, DaCosta RS, Davies JE. Nanosurfaces modulate the mechanism of peri-implant endosseous healing by regulating neovascular morphogenesis. Commun Biol. 2018 Jun 18;1:72. [Medline: 30271953] [PMC free article: 6123776] [doi: 10.1038/s42003-018-0074-y]

11. Kim HM, Miyaji F, Kokubo T, Nakamura T. Effect of heat treatment on apatite-forming ability of Ti metal induced by alkali treatment. J Mater Sci Mater Med. 1997 Jun;8(6):341-7. [Medline: 15348733] [doi: 10.1023/A:1018524731409]

12. Ban S, Iwaya Y, Kono H, Sato H. Surface modification of titanium by etching in concentrated sulfuric acid. Dent Mater. 2006 Dec;22(12):1115-20. [Medline: 16375960] doi: 10.1016/i.dental.2005.09.007]

13. Takemoto M, Fujibayashi S, Neo M, Suzuki J, Matsushita T, Kokubo T, Nakamura T. Osteoinductive porous titanium implants: effect of sodium removal by dilute $\mathrm{HCl}$ treatment. Biomaterials. 2006 May;27(13):2682-91. [Medline: 16413052] [doi: 10.1016/j.biomaterials.2005.12.014]

14. Iwaya Y, Machigashira M, Kanbara K, Miyamoto M, Noguchi K, Izumi Y, Ban S. Surface properties and biocompatibility of acid-etched titanium. Dent Mater J. 2008 May;27(3):415-21. [Medline: 18717170] [doi: 10.4012/dmj.27.415]

15. Kokubo T, Yamaguchi S. Novel Bioactive Titanate Layers Formed on Ti Metal and Its Alloys by Chemical Treatments. Materials (Basel). 2009 Dec 25;3(1):48-63. [PMC free article: 5510171] [doi: 10.3390/ma3010048]

16. Kobatake R, Doi K, Oki Y, Umehara H, Kawano H, Kubo T, Tsuga K. Investigation of effective modification treatments for titanium membranes. Appl Sci. 2017 Oct;7(10):1022. [doi: 10.3390/app7101022]

17. Kobatake R, Doi K, Kubo T, Makihara Y, Oki Y, Yokoi M, Umehara H, Tsuga K. Novel fabrication of porous titanium by a resin-impregnated titanium substitution technique for bone reconstruction. RSC Adv. 2019 Jan;9(3):1625-31. [doi: $10.1039 /$ C8RA08744J]

18. Jimbo R, Sawase T, Baba K, Kurogi T, Shibata Y, Atsuta M. Enhanced initial cell responses to chemically modified anodized titanium. Clin Implant Dent Relat Res. 2008 Mar;10(1):55-61. [Medline: 18254741] [doi: 10.1111/j.1708-8208.2007.00061.x]

19. Wang G, Li J, Lv K, Zhang W, Ding X, Yang G, Liu X, Jiang X. Surface thermal oxidation on titanium implants to enhance osteogenic activity and in vivo osseointegration. Sci Rep. 2016 Aug 22;6:31769. [Medline: 27546196] [PMC free article: 4992888] [doi: 10.1038/srep31769]

20. Juodzbalys G, Sapragoniene M, Wennerberg A. New acid etched titanium dental implant surface. Stomatol Baltic Dent Maxillofac J. 2003 Jan;5(3):101-5. [URL: https://sbdmj.com/033/033-05.html]

21. Kaur M, Singh K. Review on titanium and titanium based alloys as biomaterials for orthopaedic applications. Mater Sci Eng C Mater Biol Appl. 2019 Sep;102:844-862. [Medline: 31147056] [doi: 10.1016/j.msec.2019.04.064]

22. Van Gestel T, Vandecasteele C, Buekenhoudt A, Dotremont C, Luyten J, Van der Bruggen B, Maes G. Corrosion properties of alumina and titania NF membranes. J Membr Sci. 2003 Mar;214(1):21-9. [doi: 10.1016/S0376-7388(02)00517-3]

23. Hirota M, Ikeda T, Sugita Y, Ishijima M, Hirota S, Ogawa T. Impaired osteoblastic behavior and function on salivacontaminated titanium and its restoration by UV treatment. Mater Sci Eng C Mater Biol Appl. 2019 Jul;100:165-177. [Medline: 30948050] [doi: 10.1016/j.msec.2019.03.008] 
24. Camargo WA, Takemoto S, Hoekstra JW, Leeuwenburgh SCG, Jansen JA, van den Beucken JJJP, Alghamdi HS. Effect of surface alkali-based treatment of titanium implants on ability to promote in vitro mineralization and in vivo bone formation. Acta Biomater. 2017 Jul 15;57:511-523. [Medline: 28499630] [doi: 10.1016/j.actbio.2017.05.016]

25. Umehara H, Kobatake R, Doi K, Oki Y, Makihara Y, Kubo T, Tsuga K. Histological and Bone Morphometric Evaluation of Osseointegration Aspects by Alkali Hydrothermally-Treated Implants. Appl Sci. 2018 Apr;8(4):635. [doi: 10.3390/app8040635]

26. Kim HM, Himeno T, Kawashita M, Lee JH, Kokubo T, Nakamura T. Surface potential change in bioactive titanium metal during the process of apatite formation in simulated body fluid. J Biomed Mater Res A. 2003 Dec 15;67(4):1305-9. [Medline: 14624517] [doi: 10.1002/jbm.a.20039]

27. Kokubo T, Takagi H, Tashiro M. Alkaline durability of BaO-TiO2-SiO2 glasses. J. Non-Cryst. Solid. 1982 Dec; 52(1-3):427-33. [doi: 10.1016/0022-3093(82)90317-9]

\section{To cite this article:}

Kobatake R, Doi K, Oki Y, Makihara Y, Umehara H, Kubo T, Tsuga K.

Comparative Study of Surface Modification Treatment for Porous Titanium

J Oral Maxillofac Res 2020;11(2):e5

URL: http://www.ejomr.org/JOMR/archives/2020/2/e5/v11n2e5.pdf

doi: $\underline{10.5037 / j o m r .2020 .11205}$

Copyright (C) Kobatake R, Doi K, Oki Y, Makihara Y, Umehara H, Kubo T, Tsuga K. Published in the JOURNAL OF ORAL \& MAXILLOFACIAL RESEARCH (http://www.ejomr.org), 30 June 2020.

This is an open-access article, first published in the JOURNAL OF ORAL \& MAXILLOFACIAL RESEARCH, distributed under the terms of the Creative Commons Attribution-Noncommercial-No Derivative Works 3.0 Unported License, which permits unrestricted non-commercial use, distribution, and reproduction in any medium, provided the original work and is properly cited. The copyright, license information and link to the original publication on (http://www.ejomr.org) must be included. 